\title{
Effects of Mixing Sequence on Alumina Prepared by Injection Molding
}

\author{
Wen-Cheng J. Wei, ${ }^{a *}$ Sha-Jong Tsai ${ }^{a}$ and Kung-Chung $\mathrm{Hsu}^{b}$ \\ ${ }^{a}$ Institute of Materials Science and Engineering, National Taiwan University, Taipei 106, Taiwan \\ ${ }^{b}$ Department of Chemistry, National Taiwan Normal University, Taipei 117, Taiwan
}

(Received 12 September 1997; accepted 23 January 1998)

\begin{abstract}
Two mixing sequences of binder system were used to prepare the feedstocks containing high purity alumina (A-16SG) powder. The properties of the feedstocks were analyzed by various techniques, including FT/IR, capillary rheometry, and TGA. Besides, the green density and pore size distribution of injection molded $\mathrm{Al}_{2} \mathrm{O}_{3}$ parts, and the sintered densities, the fracture strength and Weibull distribution of the densified test bars were measured. The results indicated that the sequence of binder addition is better adding polypropylene (PP) into preheated alumina powder, then stearic acid (SA), followed by paraffin wax (PW). This mixing step was found effective for the preparation of a good mixture of plastics/powder system to produce feedstocks with a lower viscosity and better homogeneity for injection molding. The statistics of fracture strength and the results of fractography reveal that the sintered test bars made by the better feedstocks have a uniform microstructure which is free from large cracks and pore clusters. They result in a higher fracture strength $(375 \mathrm{MPa})$ and Weibull modulus (up to 20.9) than those produced by the other process. (C) 1998 Elsevier Science Limited. All rights reserved
\end{abstract}

\section{Introduction}

Homogeneity of feedstocks is one of the important properties to produce injection molded parts of high quality. ${ }^{1}$ In order to prevent the agglomeration of powder or polymeric ingredients in the blends, an optimization of powder content, ${ }^{2,3}$ understanding the effects of surfactants ${ }^{4}$ and the

*To whom correspondence should be addressed. comparison of various mixing instruments ${ }^{5,6}$ are the topics of several research works.

Juang et al. $^{3}$ prepared a series of injection molding blends with various solid contents of alumina. They reported that the Weibull modulus and flexural strength could be optimized from the adjustment of the solid loading. The increase of homogeneous mixing and decrease of defect occurrence were the reasons for the improvement of Weibull distribution of the strength.

The improvements of the injection molding of alumina are also seen from the optimization of the amount of surfactant. ${ }^{4}$ The adsorption of stearic acid (SA) on the surface of alumina powder greatly reduces the viscosity and the abrasion of powder and binder against the wall of die. In addition, a broader range of the pyrolysis of plastic mixtures during thermal debinding is reported ${ }^{4}$ as the concentration of the surfactant increases.

The dispersion conditions of the powder in the powder/binder mixture influence the viscosity and flow pattern of the feedstocks strongly. In addition to the effects of surfactant, strong-shear mixing promotes the dispersion of ceramic powders. ${ }^{5}$ Dow et al..$^{7}$ reported that the agglomerates were broken down by strong shear forces during mixing, and shows a minimal shear force needed for the deflocculation of alumina powder in polyethylene melts.

Various mixing devices offer different levels of shear forces and mixing mechanisms, classified as either diffusive, laminar or dispersive mixings. The flow patterns which are generated in mixers directly affect the dissociation of agglomerates. Essentially, the generated shear flows need to rupture the agglomerates, including polymeric and particle aggregates, at an orientation with largest shear force. The scale of shear force generated by mixing devices is controlled by the rotation frequency, the gaps between the blades and by the shape of the blades. 
The mixing torque, the composition and homogeneity of binder/powder system profoundly influence the properties of feedstocks and injection molded parts. The present study is concerned with the effects of addition sequence of polymeric ingredients while preparing the feedstocks. There are several investigations ${ }^{3-7}$ on the role of surfactant, solid content, mixing torque and state of dispersion of powder. However, alternative mixing sequences of polymeric ingredients into the mixture during kneading have not been reported in literature. A study on the rheological properties, the density and pyrolysis of green parts, the fired density and fracture properties has been conducted. The segregation in the mixtures and defects in the sintered alumina were examined and investigated. Therefore, the evidence can differentiate the advantages and disadvantages between two mixing sequences for the preparation of alumina.

\section{Experimental}

The experiment was designed to reveal the effects of mixing sequence of polymeric additives on the properties of $\mathrm{Al}_{2} \mathrm{O}_{3}$ feedstocks. There are four ingredients used is the formulation, including alumina powder (A-16SQ Alcoa Co., USA), PP (polypropylene, PC3665(5), Taiwan Polypropylene Co., Taiwan), SA (stearic acid, Nacalai Tesque, Inc., Japan) and PW (paraffin wax, Nippon Serio, Japan). The formulation contains $85 \mathrm{wt} \% \mathrm{Al}_{2} \mathrm{O}_{3}$ powder (corresponding to $56.6 \mathrm{vol} \%$ solid loading) and $15 \mathrm{wt} \%$ of polymeric additives, which include $0.75 \mathrm{wt} \% \mathrm{SA}, 10.5 \mathrm{wt} \% \mathrm{PW}$ and $3.75 \mathrm{wt} \% \mathrm{PP}$. The binder system consists of SA/PW/PP in the ratio $5 / 70 / 25$.

There are more than 24 (4!) possible mixing sequences which can be used for the preparation of alumina feedstocks. However, if the preheating of alumina powder is needed before mixing with polymeric ingredients, two mixing sequences (assigned PI or PII) can be selected as the typical cases: the PI sequence is first mixing SA and PW with preheated alumina powder, then adding PP; the PII is in reverse sequence. The details of the mixing sequence of the mixture are shown in Table 1. The mixture was prepared by using a kneader with $650 \mathrm{~cm}^{3}$ bowl, and two sigmoidal, counter- rotating blades operating at $35 \mathrm{rpm}$.

\subsection{Injection molding of test bars}

Test bars with the dimensions $5.0 \times 4.0 \times 50.0 \mathrm{~mm}^{3}$ were prepared by using an injection molding machine (CDC-9000, SM50, Chen Hsong Machinery Taiwan Co. Ltd.). Spruce and mold temperatures were set at 170 and $40^{\circ} \mathrm{C}$, respectively.
Solvent extraction was applied by using $\mathrm{n}$-heptane which was maintained at $60^{\circ} \mathrm{C}$ After solvent debinding for $3 \mathrm{~h}$, nearly $80 \%$ of dissolvable binder was extracted. The dried specimens were then put in a thermally debinding furnace which was operated using a $2^{\circ} \mathrm{C} \mathrm{min}^{-1}$ ramp rate, to two temperatures, 250 and $450^{\circ} \mathrm{C}$, holding for $2 \mathrm{~h}$ and $10 \mathrm{~min}$, respectively. Then the test bars were presintered at $1000^{\circ} \mathrm{C}$, followed by densification at $1550^{\circ} \mathrm{C}$ for $1 \mathrm{~h}$.

\subsection{Characterization}

The viscosity of two feedstocks was measured by a capillary viscometer installed on a MTS dynamic testing machine (MTS 810, MTS Co., USA). The calibration of the capillary dies with respect to the pressure drop was also conducted to improve the accuracy of the viscosity data. The displacement and the speed of extrusion were recorded, and the apparent viscosity $(\eta)$ was calculated according to a modified Rabinowitsh equation ${ }^{8}$ to reveal the characteristics of a pseudoplastic behavior of the feedstocks.

The interactions between binder components and alumina powder were analyzed by observing the shifting of the polar functional groups in the transmission IR spectra. The materials to be tested were dry mixed with $\mathrm{KBr}$ powder and then pelleted. All the spectra of the feedstocks were measured and collected using an IR spectrometer (FT/ IR 5300, Jasco Co., Japan).

Thermo-gravimetric analysis (TGA) was conducted on the Thermal Analyst 2000 (E. I. DuPont de Nemours \& Co., Inc., USA). A small amount of the specimen ( 5 to $10 \mathrm{mg}$ ) was sampled from different parts of the injection molding pieces. The test conditions were conducted in air and operated at a heating rate of $10^{\circ} \mathrm{C} \mathrm{min}^{-1}$ to a temperature of $600^{\circ} \mathrm{C}$.

The pore size distribution of the thermal-debound test bars prepared by either PI or PII sequence was determined by $\mathrm{Hg}$ porosimeter (Autopore II 9220, Micromeritics Instrument Co., USA). The test pieces were sampled either from the $1 / 3$ of the test bar close to the gatc or from whole test bar.

Green density and fired density of injection molded alumina were determined by the Archimedes method. The fracture surfaces and injectionmolded samples after solvent debinding were observed by SEM (mini-SEM, JEOL Ltd., Japan) which could reveal the distribution of the non-dissolvable PP and the flaws induced during solvent debinding. The fracture strength of fired specimens was determined by a four-point bending method, using an upper span of $10 \mathrm{~mm}$ and lower span of $20 \mathrm{~mm}$ (JIS, 1607 or CNS 12701 standard). The cross head speed was set at $0.5 \mathrm{~mm} \mathrm{~min}^{-1}$. 
Table 1. Mixing sequence of process I (PI) and process II (PII)

\begin{tabular}{|c|c|c|c|c|c|}
\hline \multicolumn{3}{|c|}{$P I$} & \multicolumn{3}{|c|}{ PII } \\
\hline $\begin{array}{l}\text { Time } \\
(\min )\end{array}$ & Operation & $\begin{array}{c}\text { Temperature } \\
\text { of mixer }\left({ }^{\circ} \mathrm{C}\right)\end{array}$ & $\begin{array}{l}\text { Time } \\
(\min )\end{array}$ & Operation & $\begin{array}{l}\text { Temperature of } \\
\text { mixer }\left({ }^{\circ} \mathrm{C}\right)\end{array}$ \\
\hline 0 & Preheating $\mathrm{Al}_{2} \mathrm{O}_{3}$ & 100 & 0 & Preheating $\mathrm{Al}_{2} \mathrm{O}_{3}$ & 100 \\
\hline 0 & Adding $\mathrm{SA}$ & 100 & 0 & Adding PP & Ramping \\
\hline 6 & Adding PW & 100 & 9 & Mixing & 175 \\
\hline 9 & Adding PP & $\begin{array}{l}\text { Ramping } \\
\text { to } 175\end{array}$ & 60 & Adding SA & $\begin{array}{l}\text { Cooling to } \\
\text { room temperature }\end{array}$ \\
\hline 18 & Mixing & 175 & 66 & $\begin{array}{l}\text { Adding PW, } \\
\text { keep mixing }\end{array}$ & Cooling \\
\hline 90 & $\begin{array}{l}\text { Cooling to room } \\
\text { temperature }\end{array}$ & 120 & & & Off \\
\hline 150 & & Off & & & \\
\hline
\end{tabular}

\section{Results and Discussion}

Figurc 1 shows the IR spectra for the binder components or mixtures with or without the presence of the alumina powder. For pure stearic acid or SA-containing binders without powder, an absorption peak, which denotes the carbonyl $(\mathrm{C}=\mathrm{O})$ group of stearic acid in a dimerized state, occurred at a frequency of about $1700 \mathrm{~cm}^{-1}$. The exact frequency of this group depends on the

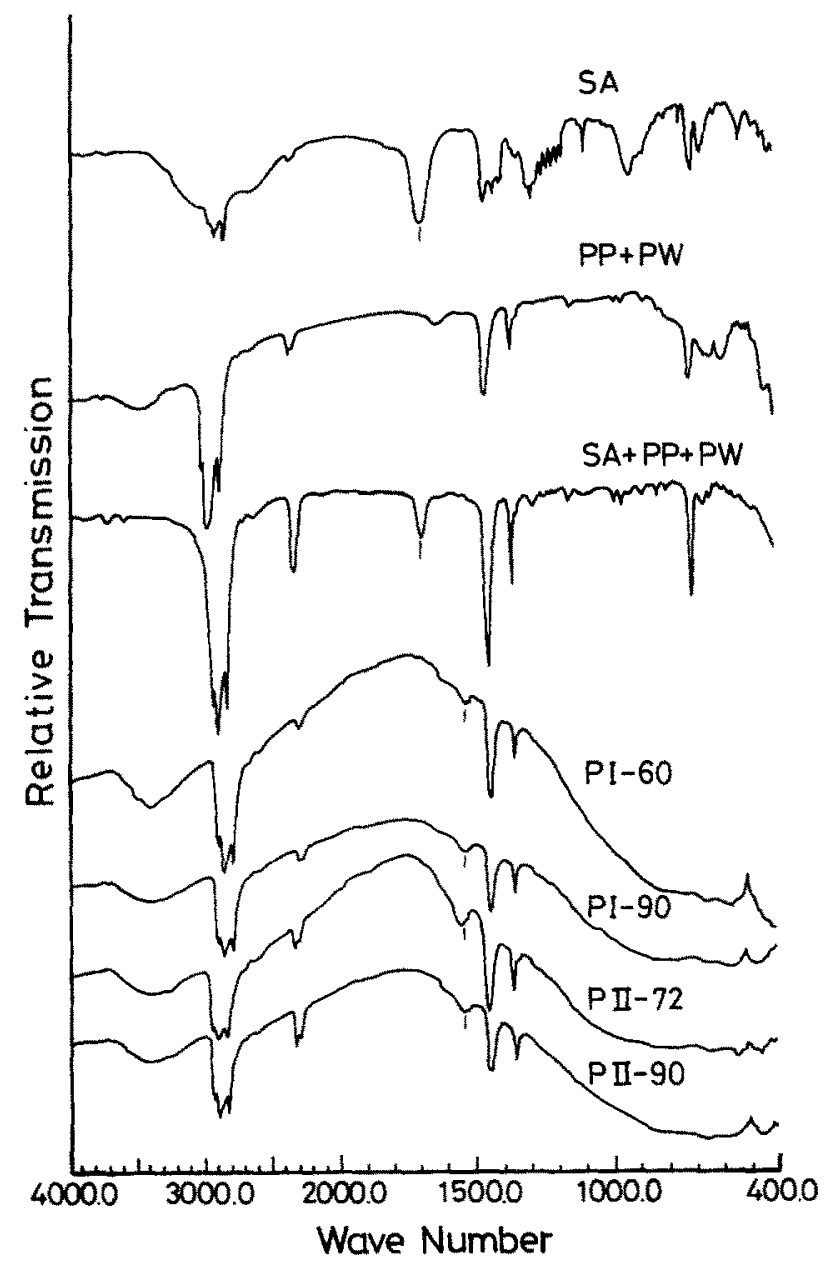

Fig. 1. Inferred spectra for binder components or mixtures with or without the presence of the alumina powder. The symbol, e.g. 'PI-60', next to the spectrum, means that the feedstocks was prepared by process PI and sampled at $60 \mathrm{~min}$ during kneading. nature of the neighboring groups. ${ }^{9}$ However, this peak would disappear when binders containing SA were mixed with powder such as these feedstocks by PI or PII, and a new peak at about $1560 \mathrm{~cm}^{-1}$ emerged instead. A similar phenomenon was also found by Chan and Lin. ${ }^{4}$ They proposed two possible explanations: first, stearic acid was adsorbed onto the alumina powder surface and reacted with the aluminum ions to form acid salts by its carboxylate ions $\left(\mathrm{COO}^{-}\right)$. The new peak at about $1560 \mathrm{~cm}^{-1}$ corresponds to newly formed carboxylate ions. The second proposal was that the peak was a shifting of the carbonyl peak from about $1700 \mathrm{~cm}^{-1}$ due to an acid-base reaction. As the formation of hydrogen bondings in the system could only result in small shifting $\left(\sim 20 \mathrm{~cm}^{-1}\right)$ of the $\mathrm{C}=\mathrm{O}$ stretching peak. the first reason seems to be more acceptable. ${ }^{9,10}$ It is clear that the absorption peak at about $1560 \mathrm{~cm}^{-1}$ was observed in either PI or PII mixtures. This indicates that SA would indeed interact with powder and act as a surfactant and/or a lubricant in the mixtures for both mixing sequences. In addition, the relative intensity of this peak decreased with mixing time for either mixing sequences indicating a minute loss of the volatile binder components during mixing.

The viscosity of two feedstocks tested at the temperatures from 160 to $180^{\circ} \mathrm{C}$ is shown in Fig. 2 . The melts of both blends show a flowing behavior of pseudo-plasticity, but the viscosity of the PI is higher than that of $\mathrm{PH}$ in the tested temperatures.

If the relation of viscosity versus shear rate is formulated by a power law model:

$$
\eta=K \dot{\gamma}^{n-1} \text { or } \ln \eta-\ln K=(n-1) \ln \dot{\gamma}
$$

where $\eta$ is the apparent viscosity of blend, $K$ is a constant to represent a viscosity at shear rate equal to $1, n$ is a flow behaviour index, and $\dot{\gamma}$ is the shear rate. The vales of $n$ and $K$ can be calculated and are shown in Table 2. It is noted that the $n$ value of PII 


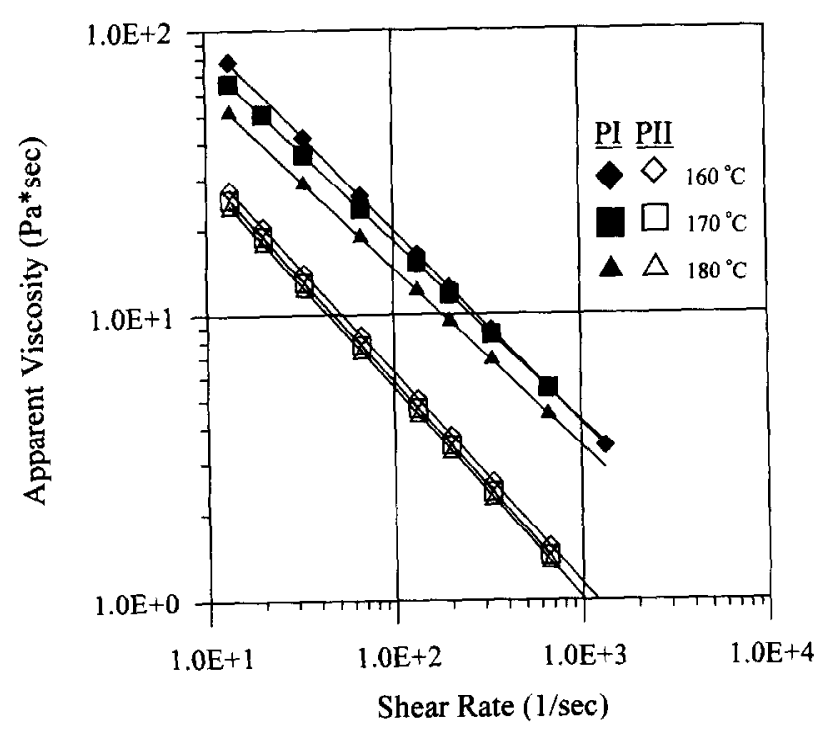

Fig. 2. Apparent viscosity plotted against shear rate of the feedstocks PI and PII tested at various temperatures by capillary viscometry.

Table 2. The flow index $n$ and constant $K$ of two blends tested at 160,170 or $180^{\circ} \mathrm{C}$

\begin{tabular}{lccc}
\hline Sample & Test temperature $\left({ }^{\circ} \mathrm{C}\right)$ & $n$ & $K$ \\
\hline PI & 160 & 0.32 & 440 \\
PI & 170 & 0.37 & 335 \\
PI & 180 & 0.38 & 250 \\
PII & 160 & 0.27 & 190 \\
PII & 170 & 0.27 & 185 \\
PII & 180 & 0.27 & 170 \\
\hline
\end{tabular}

remains at 0.27 compared to that of PI blends in a range of 0.32 to 0.38 . In addition, the $K$ values of PI blend are in a narrower range from 170 to 190 $\mathrm{Pa}^{*}$ s than PII blend. Lin and German ${ }^{2}$ reported that low apparent viscosity and low flow yield stress are preferred for the prevention of the molding failure of alumina parts. Well dispersed condition of powder in the blends results in a low apparent viscosity and consistent rheological properties which are represented by the $n$ and $K$ indices.

The results of a TGA test of the specimens sampled from the surface or center of the green pieces are shown in Fig. 3. The total weight loss of four test specimens is in the range from 14.85 to $14.95 \%$, and the maximum rate of thermal decomposition is determined at $238 \pm 2^{\circ} \mathrm{C}$. The difference of the weight loss among these four samples is $0.1 \%$ which is within the instrumental error of the TGA test. However, the temperature difference $\left(19^{\circ} \mathrm{C}\right)$ of the maximum rate of thermal decomposition measured from the surface [Fig. 3(a)] or the center [Fig. 3(b)] of PI specimens is apparently higher than the difference in PII. Comparing to the temperature difference $\left(4^{\circ} \mathrm{C}\right)$ of PII specimens, the ingredient segregation in the injection molded PI parts is possible. The segregation means that a low molecular weight polymeric ingredient is preferentially segregated onto the surface of the injection molded parts. As a result, the surface of PI parts can undergo a pyrolysis at a lower temperature than the center.

The segregation of polymeric ingredients in molded parts is not found in the literature, except one reported by Lin and German. ${ }^{5}$ They found that the TGA profiles are different for different locations, either gate, center or end, of the injection molded alumina specimen. But they reported that this was due to the different initial test weights of specimens, and claimed no separation of binder from the powder. But an observation ${ }^{11}$ of the orientation of ceramic particles and binders during injection molding revealed a predominant direction of the ingredient. The organic binders and platy powders tended to orientate along the injection flow direction in the subsurface of the green body. The injection flow, which has a greater shear rate at the central portion of mold, might also play an important role in the driving force for the segregation of low-molecular-weight binders to the surface of injection molded parts. The segregation of the binders can be judged from the following microstructural results.

A detailed analysis of the binder segregation of two samples with solvent debinding is shown in Fig. 4. The microstructure of the surfaces of PI and PII parts appear to be different. The former has surface flaws and fine fibrous features, indicated in Fig. 4(a). The fibrous features which are PP (not dissolved in $\mathrm{n}$-heptane) have a diameter less than $0.5 \mu \mathrm{m}$ occasionally identified from the fracture surfaces of PI part [Fig. 4(b)]. But the flaws and PP fibers are hardly found in PII parts, as the example shown in Fig. 4(c). The surface flaws are originally occupied with solvent-dissolvable PW and SA. The compounding of PP with PW and SA is not complete by PI process. Therefore, the segregation of PW and SA in the PI parts during injection molding is possible and generates a faster rate of solvent debinding on the surface. That would introduce surface flaws and likely result in a tensile stress on the surface.

The pore size distributions of the thermallydebound PI or PII specimens are shown in Fig. 5. The distributions of the porosity in PI and PII measured from different portions of test bars are hardly differentiable from these curves. They are in the range of 0.01 to $0.20 \mu \mathrm{m}$ and hardly greater than $0.2 \mu \mathrm{m}$, which may represent the flaws of a few $\mu \mathrm{m}$ size shown in Fig. 4(a). The flaws merely formed on the surface of the PI specimen cannot be detected by the $\mathrm{Hg}$ porosimetry. The size distribution of the porosity is nearly identical for PI and PII specimens. 

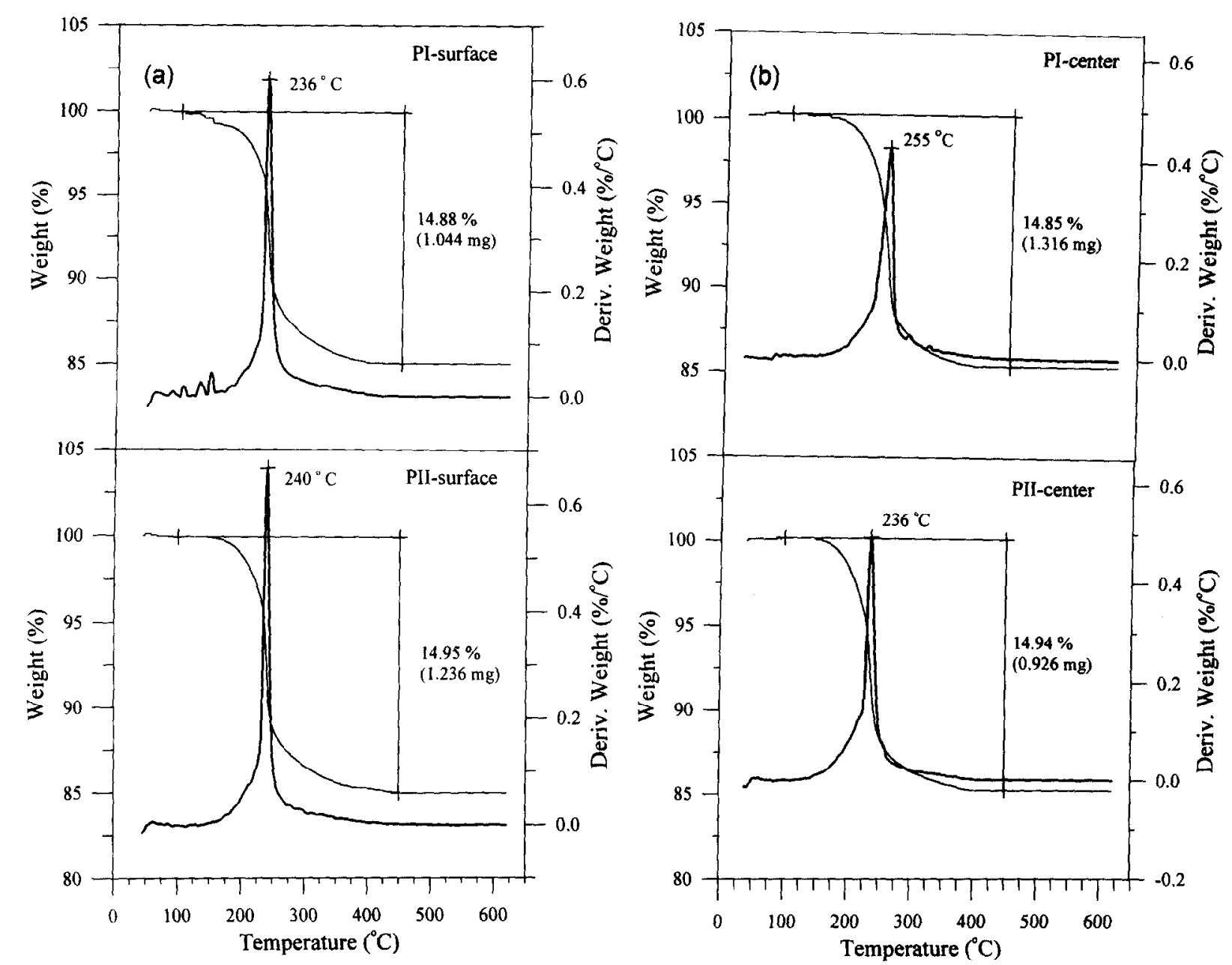

Fig. 3. TGA histograms and the derivative of weight loss of injection molded parts prepared by PI and PII sampling from (a) surface and (b) center.

The results of the pore size of the A-16SG alumina are compared to the specimen prepared by pressure casting of colloidal suspension ${ }^{12}$ also shown in Fig. 5. The size of the pore and total porosity in injection molding parts are on average greater than those prepared by an aqueous solution. ${ }^{12}$ The binder between submicrometric particles in the injection molded parts may have formed an absorbed layer in a thickness of $0.03 \mu \mathrm{m}$ greater than that in the case of colloidal casting piece. That explains why the green density of the injection molded parts is always lower than those prepared by the colloidal process.

The green density and fired density of two injection molded parts were measured and are reported in Table 3 . The density values of two specimens fall in the range of $2.61 \pm 0.01 \mathrm{~g} \mathrm{~cm}^{-3}$. The error bars of the densities of PI and PII are indeed overlapping. The fired specimens are in a range of $98.4 \pm 0.3 \%$ theoretical density (T.D.). However, the fracture strength of two specimens are quite different, the average strength of the PII is $375 \mathrm{MPa}$, a value $22 \%$ above that of the PI specimen. Moreover, the variation of the strength of PII (45 MPa) is smaller than that of PI $(67 \mathrm{MPa})$. The Weibull statistics of the strength data of PI and PII series are plotted against the fracture probability and shown in Fig. 6. The test bars of PII have performed a better strength distribution than PI specimens.

Normally, the strength and Weibull modulus $(m)$ of alumina ceramics are $380 \pm 60 \mathrm{MPa}$ and $11 \pm 4$, respectively. ${ }^{13}$ It is noted that the strength data in Fig. 6 shows a two-mode character and can be fitted to two slopes. Measured from different parts of the data points, the Weibull modulus $\left(m_{2}\right.$ and $\left.m_{1}\right)$ of PI specimens is either 4.9 or 16.2 , smaller than those $\left(m_{4}=8.7\right.$ or $\left.m_{3}=20.9\right)$ of PII specimens. The PII specimens have stronger and more consistent properties than PI specimens.

The average strength of PI is degraded by the test bars which are fitted with $m_{1}$ slope. It is necessary to examine these test bars to find the types of fracture origin. Three typical cases of the fracture surfaces are shown in Fig. 7. The central lines (marked ' $\mathrm{C}$ ') of the features in Fig. 7 are the surface stood for the tensile stress. Several large defects were identified from the features revealed by a dye penetration. These defects are half-penny cracks, long flaws, and core-shape cracks of a dimension greater than $1.5 \mathrm{~mm}$. The size of defects is too big to stand the bending moment during a 

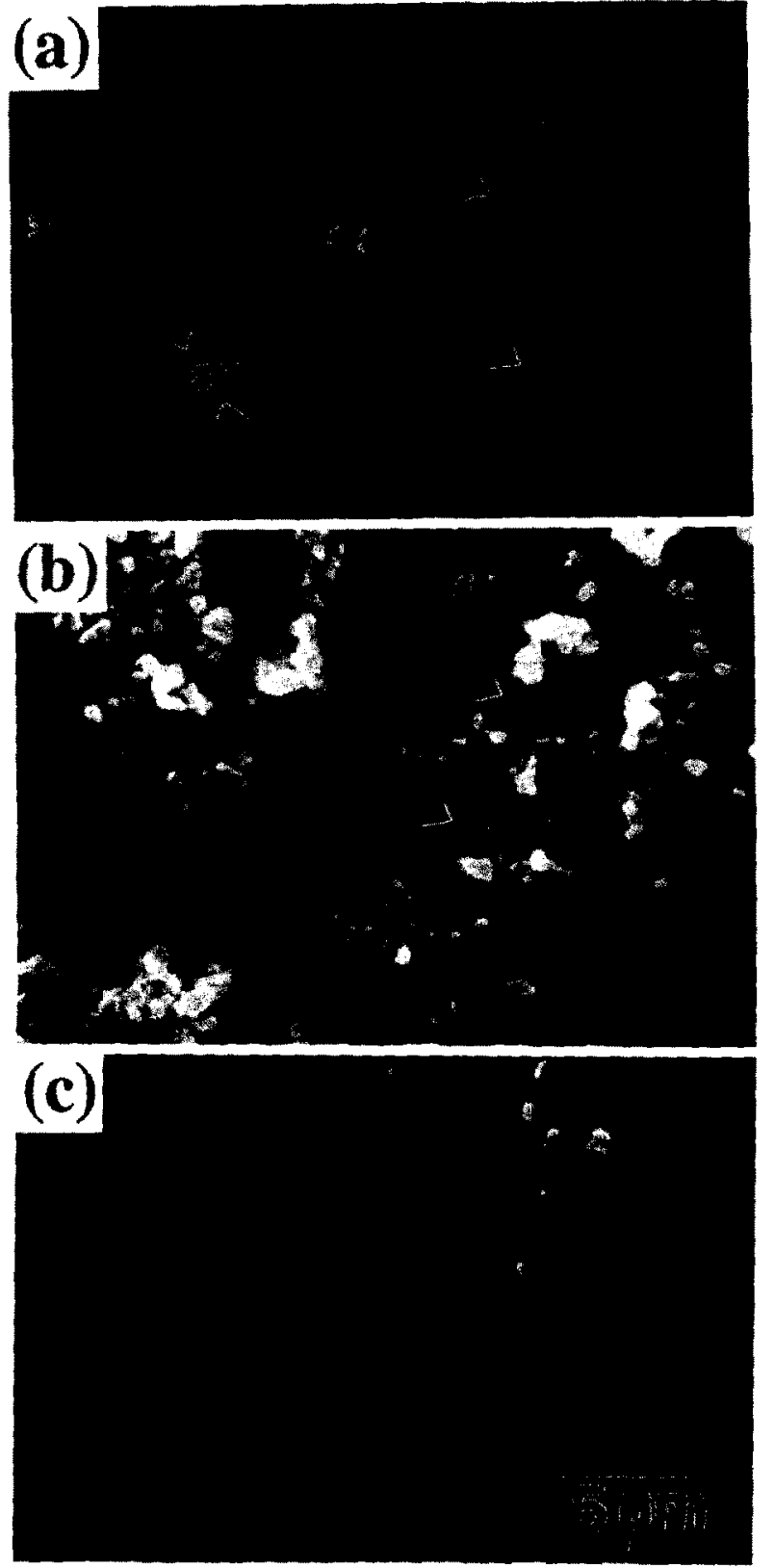

Fig. 4. SEM micrographs of (a) the surface, (b) the fractured surface of PI and (c) the surface of PII specimens after solvent debinding.

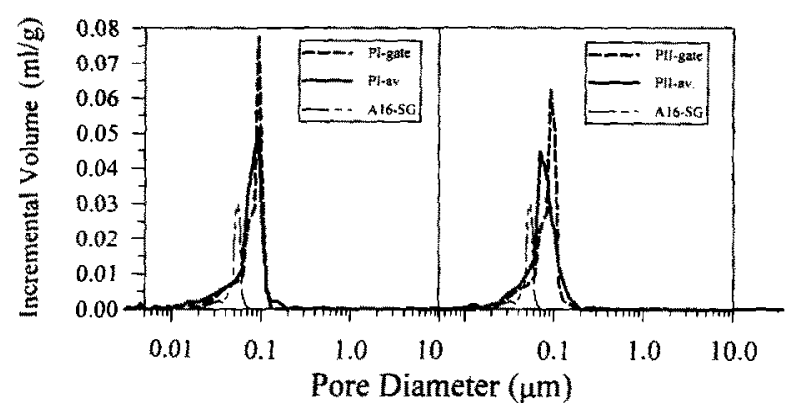

Fig. 5. Pore size distributions of thermally-debound PI and PII sampling from whole test bar (ave.) or 1/3 (near gate) of the test bar, also the pore sizes of the A-16SG alumina prepared from colloidal casting. ${ }^{10}$

4-point test. The strengths of these poor PI test bars are all less than $205 \mathrm{MPa}$.

High apparent viscosity and poor homogeneity of PI blend were reported in the previous section.
Table 3. Green density, fired density and fracture strength of injection molded alumina sintered at $1550^{\circ} \mathrm{C}$ for $1 \mathrm{~h}$

\begin{tabular}{lccc}
\hline Sample & $\begin{array}{c}\text { Green } \\
\text { density } \\
\left(\mathrm{g} \mathrm{cm}^{-3}\right)\end{array}$ & $\begin{array}{c}\text { Relative } \\
\text { fired density } \\
(\% \text { T.D. })\end{array}$ & $\begin{array}{c}\text { Fracture } \\
\text { structure } \\
(\mathrm{MPa})^{*}\end{array}$ \\
\hline PI & $2.612 \pm 0.004$ & $98.6 \pm 0.2$ & $307 \pm 67$ \\
PII & $2.615 \pm 0.005$ & $98.2 \pm 0.2$ & $375 \pm 45$ \\
\hline
\end{tabular}

*Average from more than 40 test bars.

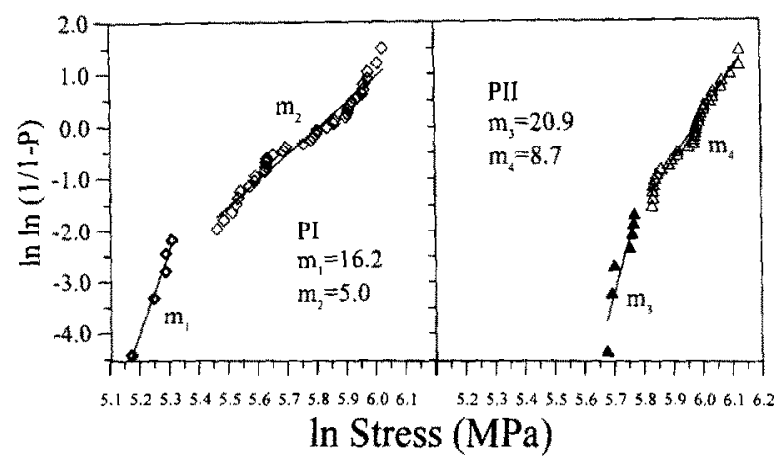

Fig. 6. Weibull plot of the fracture strength of sintered PI and PII specimens.
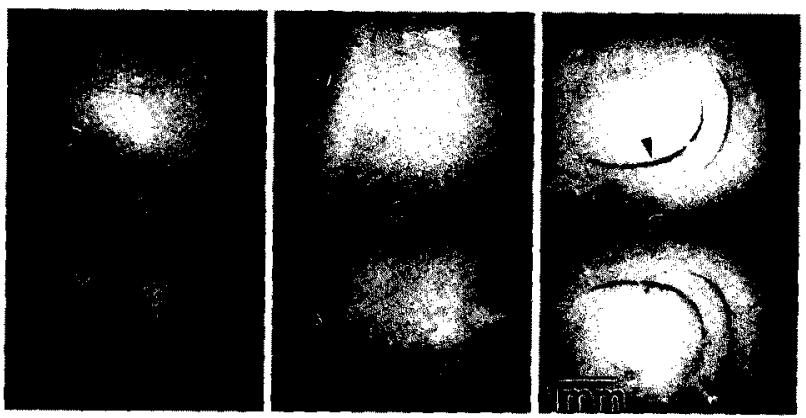

Fig. 7. Three optical micrographs of the fracture surfaces of PII test bars. The center lines (indicated as ' $c$ ') are two tensile surfaces.

The segregation of low-molecular-weight ingredients onto the surface might induce non-uniform shrinkage of the injection molded parts during de-molding and solvent debinding. The cracks and other defects were likely retained in the following processing steps of thermal debinding and sintering. Accordingly, the defects shown in Fig. 7 induced by the PI feedstocks with non-uniformity and higher viscosity are responsible for the poor quality of fracture strength of $\mathrm{PI} \mathrm{Al}_{2} \mathrm{O}_{3}$.

\section{Conclusion}

High-purity, submicron $\mathrm{Al}_{2} \mathrm{O}_{3}$ powder was blended with the binder system, including PP binder, PW plasticizer and SA surfactant. Experimental results indicated that the mixing sequence for binder addition in $\mathrm{Al}_{2} \mathrm{O}_{3}$ powders should be to add $\mathrm{PP}$ first, followed by stearic acid and PW. The mixing sequence (PII) was shown to produce well-mixed 
$\mathrm{Al}_{2} \mathrm{O}_{3}$ feedstocks with a lower viscosity and better pseudoplasticity, less segregation of polymeric ingredients, smaller size in powder agglomerate and good mold filling during injection molding. The relative density and fracture strength of the sintering PII specimens were measured to be $98.6 \%$ T.D. and $375 \pm 45 \mathrm{MPa}$, comparing to that $(307 \pm 67 \mathrm{MPa})$ made by the PI mixing sequence. The Weibull distribution of the strength can be greatly improved by using the PII sequence.

\section{Acknowledgement}

The authors would like to acknowledge the research funding given by National Science Council in Taiwan under the project NSC85-2216-E-002-031.

\section{References}

1. Mutsuddy, B. C. and Ford, R. G., Ceramic Injection Molding, Mat. Tech. Series. Chapman and Hall, New York, 1995

2. Lin, S. T. P. and German, R. M., The influence of powder loading and binder additive on the properties of alumina injection-moulding blends. $J$ Mat. Sci., 1994, 29, $5367-5373$.
3. Juang, H. Y. and Hon, M. H., Effect of solid content on processing stability for injection molding of alumina evaluated by Weibull statistics. J. Ceram. Soc. Jpn., 1995, 103(5), 430-433.

4. Chan, T.-Y. and Lin, S.-T., Effects of stearic acid on the injection molding of alumina. J. Am. Ceram. Soc., 1995, 78(10), 2746-2752.

5. Lin, S. T. and German, R. M., Interaction between binder and powder in injection molding of alumina. J. Mat. Sci., 1994, 29, 5207-5212.

6. Hunt, K. N. and Evans, J. R. G., The influence of mixing route on the properties of ceramic injection molding blends. Brit. Ceram. Trans. J., 1988, 87, 17-21.

7. Dow, J. H., Sacks, M. D. and Shenoy, A. V., Dispersion of alumina particles in polyethylene melts. Ceramic Powder Science, III, ed. G. L. Messing et al., 1990, pp. 431-442.

8. Bard, Y., Non-linear Parameter Estimation and Programming, IBM, New York Scientific Center, New York, 1967.

9. Silverstein, R. M., Bassler, G. C. and Morrill, T. C., Spectrometric Identification of Organic Compounds, 5th edn. John Wiley and Sons, New York, 1991.

10. Howard, K. E., Lakeman, C. D. E. and Payne, D. A., Surface chemistry of various poly(vinyl butyral) polymers adsorbed onto alumina. J. Am. Ceram. Soc., 1990, 73(8), 2543-2546.

11. Zhang, T., Blackburn, S. and Bridgwater, J., The orientation of binders and particles during ceramic injection moulding. Journal of the European Ceramic Society, 1997, 17, 101108 .

12. Cheng, S. J., MSc thesis, Process characteri of submicron $\mathrm{Al}_{2} \mathrm{O}_{3}$ and $\mathrm{Al}_{2} \mathrm{O}_{3} / \mathrm{SiC}$ powder mixtures. Figs 4-8, National Taiwan University, 1995.

13. Munro, R. G., Evaluated material properties for a sintered $\alpha$-alumina. J. Am. Ceram. Soc., 1997, 80(8), 19191928. 